\title{
Effect of Bentonite on the Coefficient of Consolidation of Soil
}

\author{
Fawad Ahmad ${ }^{1}$, Beenish ${ }^{2}$, Khalil Ur Rehman ${ }^{3}$, Afaq Ahmad ${ }^{4}$, Muhammed Armaghan Siffat ${ }^{5}$ \\ $\mathbf{1 , 2 , 3 , 4 , 5}$ Researcher and Post Graduate Student, National Institute of Urban Infrastructure Planning, University of Engineering and \\ Technology, Peshawar, Pakistan, \\ ${ }^{1 *}$ fawadahmad.civ@uetpeshawar.edu.pk, ${ }^{2 *}$ beenishbee.niuip@uetpeshawar.edu.pk, ${ }^{3 *} 14$ pwciv4117@uetpeshawar.edu.pk, \\ 4*12pwciv3857@uetpeshawar.edu.pk, ${ }^{5^{*}} \mathrm{~ms} 12$ pwciv3699@uetpeshawar.edu.pk
}

Received Date : August 03, 2021 Accepted Date : August 22, 2021 Published Date : September 07, 2021

\begin{abstract}
Bentonite is a fine clay, usually occurring as a byproduct of atmospheric weathering of volcanic ash. It is widely known for its capabilities of high absorption of moisture, and swelling, as a result of moisture contact. Bentonite has a crystalline structure with the main constituent as montmorillonite which has a dual-layered structure. It is the main ingredient responsible for imparting valuable properties to bentonite. In this study, several samples were tested from different regions of district Mardan, Pakistan, to analyze the collective effect of bentonite on the region's soil. An analysis was conducted based on the performed tests on the samples, to predict the consolidation behavior when samples were replaced with $0 \%, 5 \%, 10 \%$, and $15 \%$ of bentonite by mass. Thecoefficient of consolidation gives the rate of increase of settlement or consolidation when the sample is subjected to externally applied pressure. This study observed a decrease in the coefficient of consolidation of soil with the percentage increase of bentonite reaching a minimum value of 0.005 $\mathrm{in}^{2} /$ min showing about four times decrease in the coefficient of consolidation with $15 \%$ replacement of soil with bentonite. This behavior of bentonite is attributed to the fact that; being a fine clay, its addition to the soil reduces its pores and fills the open spaces, hence reducing the chances of fluid to penetrate or flow through the soil, resulting in the reduction ofthe coefficient of consolidation $\mathrm{C}_{\mathrm{v}}$.
\end{abstract}

Key words: Bentonite, Consolidation, Coefficient of Consolidation, Consolidation behavior, Soil-bentonite behavior.

\section{INTRODUCTION}

Soil behavior is dependent upon its composition. The properties of soil depend upon the chemical and physical disintegration of the material from which it is formed as a byproduct. Soil composition can be broadly classified as containing air, in the form of voids, water, in the shape of electrolytes and plant essential nutrients, and many variants of organic and inorganic matter [1]. The structure of the soil is usually referred to as the compactness and arrangement of soil particles associated with the voids present between them [2]. One such type of variant includes bentonite clay. It is a very fine-textured soil, usually formed as a result of the chemical decomposition and weathering of volcanic ash by salts present in seawater or mountainous rainfalls[3][4]. Bentonite has a fresh look and color having a white or light brown appearance, which darkens with more exposure to the atmosphere and weathering action [5]. Bentonite is such a clay that can absorb huge quantities of moisture and increase in size multifold. Studies suggest that bentonite can swell up to eight times its original volume [5].

Bentonite clay is composed of a crystalline structure, with abundant quantities of montmorillonite. This montmorillonite is a double-layered structure with large areas for fluid entraption in between the layers. This property allows the bentonite to acquire a large surface area, hence suitable for water absorption in large quantities. These crystalline structures adhere to water as well as each other, hence having a good cohesive property which is mostly required in construction projects, making it a good binder [4][6]. Therefore, these required properties are put to use in this work, to test their applicability and usefulness using indigenous soils for better outcomes and results.

This study involves the testing of controlled samples and samples with some addition of bentonite. The samples are collected from three Tehsils of the district Mardan in Pakistan. They are blended in different proportions of $0 \%$, $5 \% 10 \%$ and $15 \%$ respectively to get a better understanding of soil-bentonite behavior. This is done to get the required properties of bentonite with the cost efficiency of using naïve soils.An analysis based on geotechnical attributes is carried out on the soils for attainment of desired qualities in the region's soil.

\section{METHODOLOGY}

This work is aimed at attaining reasonable data of soilbentonite clay using a geotechnical approach. Soil samples are collected from different regions of Takht Bhai, Katlang and Mayar, and brought to the laboratory as per ASTM Standards. The main focus is on the Consolidation Test according to ASTM D 2435 - 04[7]. This one-dimensional 
consolidation test yields us the deformation which the sample undergoesduring application of long durations of pressure; while noting the time it takes for each increment. Usually, the deformation is noted against time in the intervals of $15 \mathrm{~s}, 30 \mathrm{~s}, 1 \mathrm{~min}, 2 \mathrm{~min}, 4 \mathrm{~min}, 8 \mathrm{~min}, 15 \mathrm{~min}$, $30 \mathrm{~min}, 1 \mathrm{hr}, 2 \mathrm{hr}, 4 \mathrm{hr}$ and $24 \mathrm{hrs}$.This deformation data is collected for 24 hours for each pressure application. The pressure applied here is in the intervals of $0.2,0.4,0.8,1.6$, $3.2,6.4$ and $12.8 \mathrm{~kg} / \mathrm{cm}^{2}$. This data is used to plot a deformation versus log of time graph as shown in Figure 1.

\section{Consolidation at Pressure $=1.6 \mathrm{~kg} / \mathrm{cm} 2$}

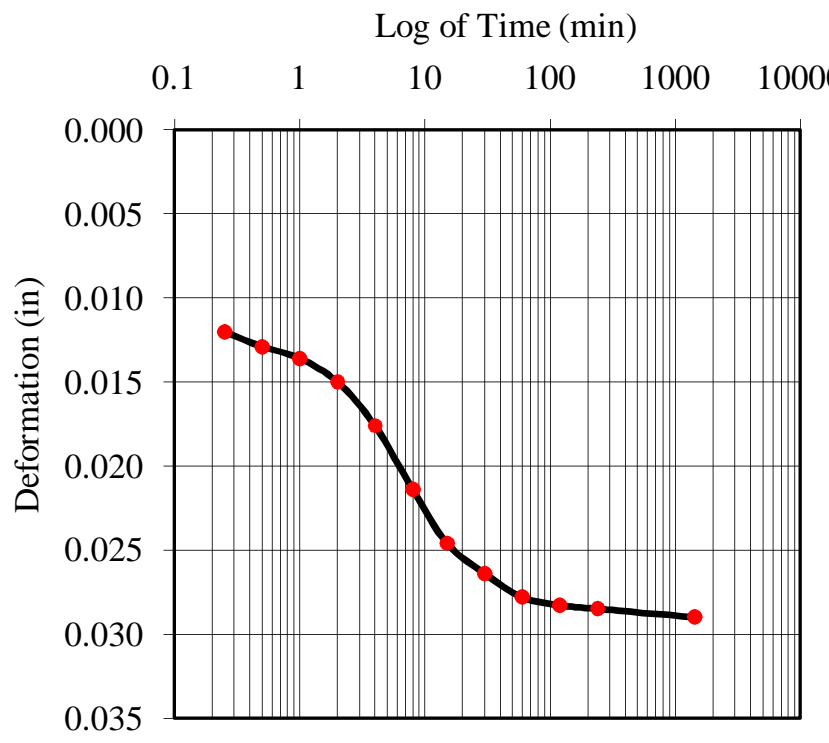

Figure 1: Deformation vs. log of Time

A typical example of the data analyzed is shown in Figure 1. In this graph, the data for the pressure of $1.6 \mathrm{~kg} / \mathrm{cm}^{2}$ is used to show the deformation curve for consolidation of soil sample during 24 hours application. The deformation is plotted against the log of time according to ASTM standards [7]to get a graph, which is in turn used to find the time and drainage path at $50 \%$ consolidation. This data is used to calculate the coefficient of consolidation $\mathrm{C}_{\mathrm{v}}$ by the equation given as shown in equation (1).

$$
C_{v}=\frac{0.197 H^{2}}{t_{50}}
$$

Where, $\mathrm{t}_{50}$ is the time at which $50 \%$ consolidation is achieved, and $\mathrm{H}$ is the length of the drainage path for $50 \%$ consolidation. This data is collected for all the samples with respective bentonite dosages, and their graphs are plotted respectively. The coefficient of consolidation $\mathrm{C}_{\mathrm{v}}$ is given for samples and relation is drawn in the graph as shown in Figure 1. The one-dimensional consolidation test setup used for testing is shown in Figure 2, while the sample preparation and sample loading is shown in Figure 3 and Figure 4 respectively.

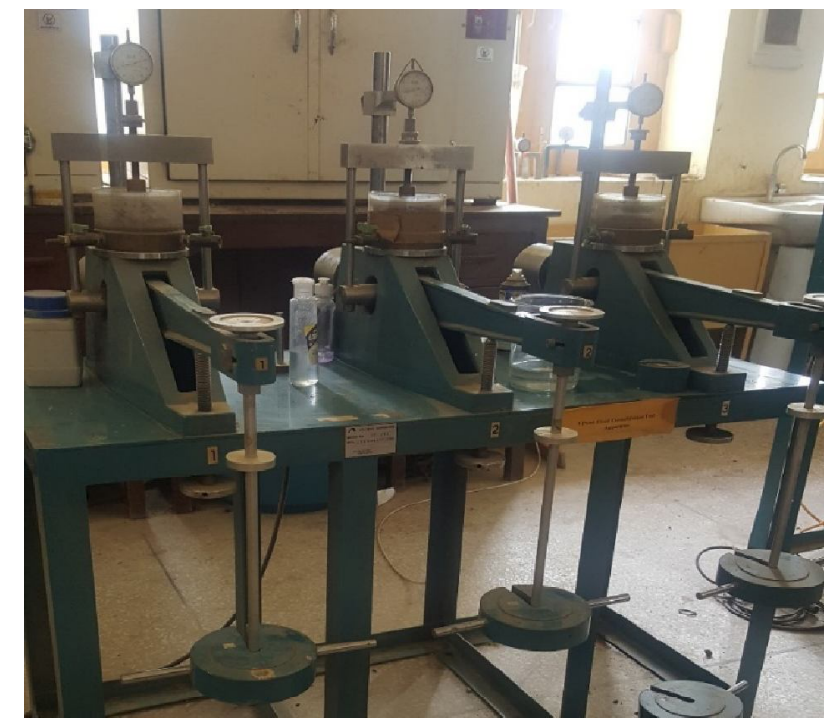

Figure 2: Consolidation Test Apparatus

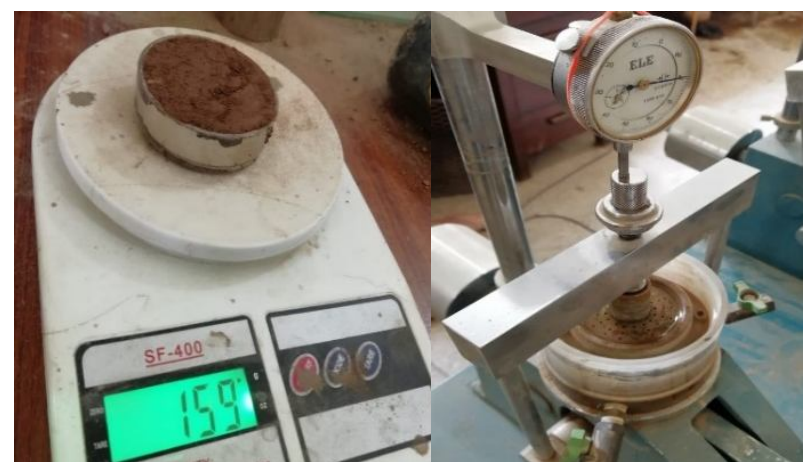

Figure 3: Sample Preparation

Figure 4: Sample Loading

\section{RESULTS AND DISCUSSION}

Consolidation is a time-dependent process in soils, which causes a change in the volume of soil by the expulsion of water from the pores[8]. It is carried out by compacting the soil with constant pressure for a certain duration of time. This allows the soil to settle and consolidate with the removal of water from its pores, hence forming a structure with closely lying soil particles with little voids spaces and moisture[9]. Thus, the samples are tested in an odometer for consolidation and deformation is noted for respective time intervals at specific pressure applications.

The obtained results from the tests performed are tabulated in Table 1 for all the samples tested. These results show a decreasing trend in the values of coefficient of consolidation $\mathrm{C}_{\mathrm{v}}$, with the percentage replacement of bentonite with soil samples. The Katlang soils exhibit a very straight line (almost linear) behavior with $\mathrm{C}_{\mathrm{v}}$, showing a constant decrease. While Mayar and Takht Bhai soils start high and 
decrease drastically with $5 \%$ bentonite replacement down to $0.01 \mathrm{in}^{2} / \mathrm{min}$. Takht Bhai soils show a negligible change in $\mathrm{C}_{\mathrm{v}}$ between $10 \%$ and $15 \%$ replacement of bentonite, whereas the minimum value is attained by $15 \%$ bentonite replacement in Katlang soils, reaching $0.0052 \mathrm{in}^{2} / \mathrm{min}$ as the coefficient of consolidation. The relationship is shown elaborately in Figure 5.

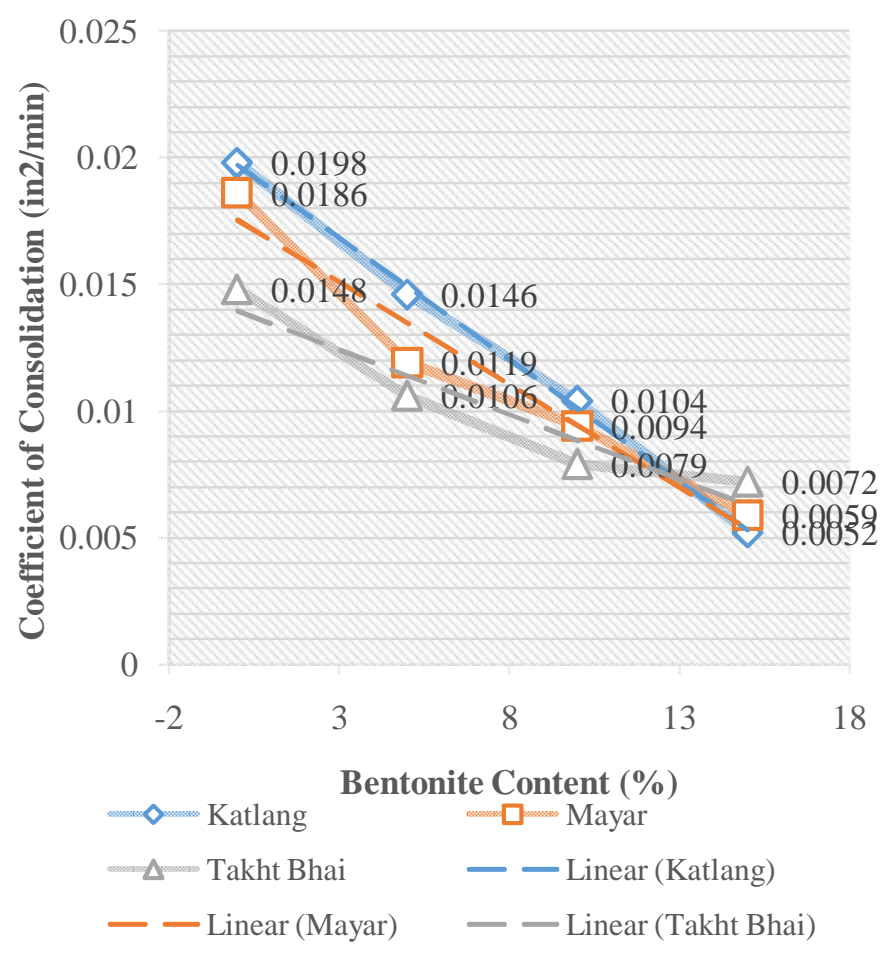

Figure 5: Coefficient of Consolidation with bentonite dosage

The solid lines represent the actual data obtained from testing of the samples shown with different marker types in the graph, while the dashed lines represent the trend lines that these soils follow in their properties of coefficient of consolidation with increasing content of bentonite. This data is represented in Table 1.

Table 1: Coefficient of Consolidation $\left(\mathrm{C}_{\mathrm{v}}\right)$ with Bentonite Content

\begin{tabular}{lcccc}
\hline \multirow{2}{*}{$\begin{array}{l}\text { Soil } \\
\text { Samples }\end{array}$} & \multicolumn{4}{c}{ Coefficient of Consolidation $\mathbf{C}_{\mathbf{v}}\left(\mathbf{i n}^{\mathbf{2}} / \mathbf{m i n}\right)$} \\
\cline { 2 - 5 } & $\begin{array}{c}\mathbf{0 \%} \\
\text { Replaced }\end{array}$ & $\begin{array}{c}\mathbf{5 \%} \\
\text { Replaced }\end{array}$ & $\begin{array}{c}\mathbf{1 0 \%} \\
\text { Replaced }\end{array}$ & $\begin{array}{c}\mathbf{1 5 \%} \\
\text { Replaced }\end{array}$ \\
\hline Katlang & 0.0198 & 0.0146 & 0.0104 & 0.0052 \\
\hline Mayar & 0.0186 & 0.0119 & 0.0094 & 0.0059 \\
\hline $\begin{array}{l}\text { Takht } \\
\text { Bhai }\end{array}$ & 0.0148 & 0.0106 & 0.0079 & 0.0072 \\
\hline
\end{tabular}

$\mathrm{R}^{2}$ is a statistical value, known as the coefficient of determination. In regression analysis, $\mathrm{R}^{2}$ is a tool used as a statistical measure of how well the real data points are plotted. It gives us an approximation of the wellness of data. The best data fit will have an $\mathrm{R}^{2}$ value of 1 , while those that don't fit will have a value less than 1 .

Thus, the data provided by the tests performed on these samples show a positive sign, as all of them fall between 0.91 and 0.998 which is very close to 1 . Thus we can say, the data is fit and shows a reliable behavior. The detailed values are shown in Table 2.

Table 2: Trend of decreasing coefficient of consolidation $\mathrm{C}_{\mathrm{v}}$ in soil samples.

\begin{tabular}{lll}
\hline Soil Samples & Trend line Equation & $\mathbf{R}^{2}$ value \\
\hline Katlang & $\mathrm{y}=-0.001 \mathrm{x}+0.0197$ & $\mathrm{R}^{2}=0.9983$ \\
\hline Mayar & $\mathrm{y}=-0.0008 \mathrm{x}+0.0175$ & $\mathrm{R}^{2}=0.9547$ \\
\hline Takht Bhai & $\mathrm{y}=-0.0005 \mathrm{x}+0.014$ & $\mathrm{R}^{2}=0.9136$ \\
\hline
\end{tabular}

\section{CONCLUSIONS}

The suitability of a soil-bentonite mixture depends upon the attainment of required results and properties in terms of geotechnical investigation. All the data collected from tests show a significant decrease in the value of the coefficient of consolidation $\mathrm{C}_{\mathrm{v}}$. We can conclude that adding $15 \%$ of bentonite to the soil decreases its $\mathrm{C}_{\mathrm{v}}$ up to four times from its original value for controlled samples, showing a decrease from $0.02 \mathrm{in}^{2} / \mathrm{min}$ down to $0.05 \mathrm{in}^{2} / \mathrm{min}$. This phenomenon is due to the possibility that increasing bentonite content causes a blockage in the flow paths of moisture, with its smaller clay particles but occupying large surface areas. The larger spaces in the sample soils are taken over by smaller bentonite clay particles, causing hindrance in fluid flow [10]. Hence with every dose of bentonite addition, the rate of consolidation decreases.

A statistical analysis has been carried out to determine the data validity of the samples collected from the population. The detailed description of the analysis is given in Table 3.This study shows the probability of data randomness of the data based on standard normal probability distribution. We can see the results, in comparison with the controlled samples, which shows that the data acquired lies in the range of reliability, which is by thumb rule, 5\% of data randomness. This means that $95 \%$ of the data is reliable while the remaining $5 \%$ data may include outliers or data points which may have occurred due to human or mechanical errors. 
Fawad Ahmad et al., International Journal of Emerging Trends in Engineering Research, 9(9), September 2021, 1230 - 1233

Table 3: Statistical Analysis of Data Randomness

\begin{tabular}{ccc}
\hline Samples & $\begin{array}{c}\text { Coefficient of } \\
\text { Consolidation } \mathbf{C}_{\mathbf{v}}\end{array}$ & $\begin{array}{c}\text { Probability of } \\
\text { Data Randomness }\end{array}$ \\
\hline 5\% Bentonite & 0.0146 & \\
Replaced & 0.0119 & $4.85 \%$ \\
& 0.0106 & \\
10\% Bentonite & 0.0104 & \\
Replaced & 0.0094 & \\
& 0.0079 & \\
& & \\
15\% Bentonite & 0.0052 & $0.55 \%$ \\
Replaced & 0.0059 & \\
& 0.0072 & \\
\hline
\end{tabular}

For the bentonite replacement of $5 \%$, the probability comes out as 0.0485 which means it is below $5 \%$ whereas the $10 \%$ and $15 \%$ bentonite replaced soils show the randomness probability to a very small number between 0.0147 and 0.0055 which is less than $1 \%$ probability that an outlier will be present in the data. The blue color shows that the data is significant, while the red color data shows the inconclusiveness of the given data. Since there is no red colored data, all the test values obtained can be termed significant and hence conclusive for the desired outcomes. Hence it can be concluded that bentonite addition causes the coefficient of consolidation $\mathrm{C}_{\mathrm{v}}$ to decrease.

\section{REFERENCES}

[1] "Composition and Physical Properties of Soils," vol. 13, pp. 1-36, Jan. 1983, doi: 10.1016/S01662481(08)70048-5.

[2] B. V. Ranganatham, "Soil structure and consolidation characteristics of black cotton clay," Geotechnique, vol. 11, no. 4, pp. 333-338, 1961, doi: 10.1680/geot.1961.11.4.333.

[3] W. M. Sutherland, "Wyoming bentonite," Catal. from $A$ to $Z, \quad 2020, \quad$ doi: 10.1002/9783527809080.cataz18044.

[4] "Introduction to mineralogy," Choice Rev. Online, vol. 37, no. 11, pp. 37-6290-37-6290, 2000, doi: 10.5860/choice.37-6290.

[5] J. A. Jackson, “'Bentonite'. Glossary of geology (Fourth ed.). ISBN 0922152349," 1997.

[6] R. I. Barnhisel, "Introduction to Mineralogy," Soil Sci. Soc. Am. J., vol. 34, no. 4, pp. iv-iv, 1970, doi: 10.2136/sssaj1970.03615995003400040003x.

[7] ASTM D2435, "Standard Test Methods for OneDimensional Consolidation Properties of Soils Using Incremental Loading," ASTM Stand, vol. 04, no. June, pp. 1-10, 2003.

[8] A. Thurairajah, Critical state soil mechanics, vol. 16, no. 3-4. McGraw-Hill, 1988.

[9] I. K. Lee, Soil mechanics Soil mechanics, Illustrate. Wiley, 2006.

[10] H. Komine, "Simplified evaluation on hydraulic conductivities of sand-bentonite mixture backfill," Appl. Clay Sci., vol. 26, no. 1-4 SPEC. ISS., pp. 1319, 2004, doi: 10.1016/j.clay.2003.09.006. 